\title{
The Canadian Epilepsy Database and Registry
}

\author{
R.S. McLachlan
}

\begin{abstract}
Epilepsy encompasses medical, psychological, social and demographic factors which are best studied in large populations. The Canadian Epilepsy Database and Registry (CEDAR) is a comprehensive English language, multicentre epilepsy database which has been developed to study the impact of these and other factors on epilepsy in Canada. In addition, it can be used locally in the clinic for office record keeping, automated printout of a referral letter or graphing seizures and other data over time. The data in CEDAR are similar to what is found in the patient's chart. There are 20 participating centres across Canada which have entered data on over 8000 adult and pediatric epilepsy patients. The information in CEDAR will be available for research purposes to centres entering data as well as to academic researchers, the pharmaceutical industry and government agencies.
\end{abstract}

\begin{abstract}
RÉSUMÉ: La Banque de données et le Registre canadien de l'épilepsie. L'épilepsie comprend des facteurs médicaux, psychologiques, sociaux et démographiques qu'on peut mieux étudier dans des grandes populations. La Banque de données et le Registre canadien de l'épilepsie (BRCÉ) est une banque de données étendue, multicentre, en anglais, sur l'épilepsie qui a été développée pour étudier l'impact de ces facteurs et d'autres facteurs sur l'épilepsie au Canada. De plus, elle peut être utilisée localement en clinique pour la tenue de dossiers, pour imprimer automatiquement une lettre, pour référer un patient ou pour dessiner un graphique des crises ou d'autres données dans le temps. Les données dans BRCÉ sont semblables à ce qu'on retrouve dans le dossier du patient. Les 20 centres participants à travers le Canada ont entré des données sur plus de 8000 adultes et enfants épileptique. L'information dans BRCÉ sera mis à la disposition des chercheurs des centres qui entrent des données, des chercheurs du milieu académique, de l'industrie pharmaceutique et des agences gouvernementales, à des fins de recherche.
\end{abstract}

Can. J. Neurol. Sci. 1998; 25: S27-S31

The astounding impact of computerization on medical practice and research over recent years can be illustrated by many examples. Imaging of the human body using computer techniques for diagnosis and clinical research is commonplace. No secretary would be without a powerful word processor which has replaced the electric typewriter used in most offices only 15 years ago. Not surprisingly, computers designed to store, organize and retrieve large amounts of information are also emerging as important tools for clinical database development and management. The purpose of this article is to briefly describe the recent development and potential usefulness of a Canadian epilepsy database.

Over the past 10 years, more and more individual physicians have attempted to develop working clinical databases for their own offices or clinics with varying degrees of success. Early software platforms for database development were cumbersome and many physicians did not appreciate the time and effort required to establish a useable database. It was on this background that the Canadian Epilepsy Database and Registry (CEDAR) was designed as the first English language national epilepsy database in the world and one of the first widely used, disease oriented software programs. ${ }^{1}$ The only other country to have developed a successful multicentre, comprehensive epilepsy database is Italy. ${ }^{2}$

The concept for a national epilepsy database took form in 1994 when a pediatric neurology consortium was established under the leadership of Dr. Joe Dooley from Halifax with startup funding from Parke Davis. One of the goals of this consortium was to develop and implement a pediatric epilepsy database. In 1995, Dr. Dooley and I discussed including epilepsy of all ages in the database which could then be used by both adult and pediatric neurologists on a national basis. The original concept was to have two databases, one for pediatrics and one for adult epilepsy, but it quickly became apparent that the degree of overlap was so great that one combined database would be most appropriate. Thus, CEDAR was born under the auspices of the Canadian League Against Epilepsy (CLAE) with financial support from Burroughs Wellcome followed by Glaxo Wellcome.

The main purpose of CEDAR is to assist in the establishment of a disease specific research network to enhance epilepsy research in Canada. The information in CEDAR is of potential use to academic researchers, the pharmaceutical industry and government agencies. CEDAR can provide detailed information from large numbers of patients on epidemiology, genetics, seizure types, epilepsy syndromes, antiepileptiec drug doses or

From the London Health Sciences Centre, University of Western Ontario, London. Based on a lecture given at Glaxo Wellcome in Mississauga in September 1997. Reprint requests to: Richard S. McLachlan, M.D., University of Western Ontario, London Health Sciences Centre, University Campus, 339 Windermere Road., London, Ontario, Canada N6A 5A5 
adverse effects, efficacy of treatment over time, quality of life and any combination of these. Anyone who wishes access to data in CEDAR must submit a proposal in writing to the executive committee of the CLAE who will determine if the request is reasonable and if there are costs involved. Since the information regarding patients in the national database is anonymous, any research requiring further patient contact can be done through individual participating centres with the patient's consent. Subsequent to the development of CEDAR, a Canadian Epilepsy Consortium (CEC) was formed with a mandate of focusing on, encouraging and coordinating multicentre research trials in epilepsy in Canada. The CEC/CEDAR initiatives are complimentary to one another and provide a powerful resource for industry and government funded epilepsy research in this country.

More than two years of work by many people including numerous clinicians and two software programmers was required before CEDAR version 1.0 was available for distribution to Canadian epilepsy centres in February, 1997. During development, as pediatric and adult neurologist across the country submitted suggestions for content, it became apparent that CEDAR could not only be used as a research tool, but as a practical office resource for following and analyzing patient data in individual clinics. Much effort was directed at making CEDAR as users friendly as possible by incorporating mouse-driven menus and pick lists throughout.
The end result is a Windows based program using Microsoft Access 2.0, the best platform available at the time, with ability to run on individual personal computers as well as networks. CEDAR runs best on a Pentium computer with at least 16 megabytes of RAM and an SVGA monitor. It is not yet available for Macintosh users. There are 13 data screens (Figures 1 and 2 are examples) as well as pregnancy and surgery screens. The content and structure resemble what would be found in a patient's chart, including history, physical, diagnosis, investigations, treatment, quality of life and follow-up. The International Classification of Seizures ${ }^{3}$ and the International Classifications of Epilepsies ${ }^{4}$ are used to document seizures and syndromes; details regarding seizure frequency and type as well as dose and side effects of antiepileptic drugs are updated at each return visit of the patient. CEDAR version 2.0, based on feedback from users who entered the first 5000 patients, incorporates automatic data analysis for individual clinics. It also has graphing capability for data collected over time such as individual response to antiepileptic drugs and the ability to generate a summary letter for the referring physician. It will also print a Patient Summary page of commonly required information (Figure 3 ). Examples of the type of data available from CEDAR are seen in Tables 1 and 2. Figure 4 shows a sample graph.

In order to make CEDAR as user-friendly as possible, we elected to leave out specific data fields which were of interest to

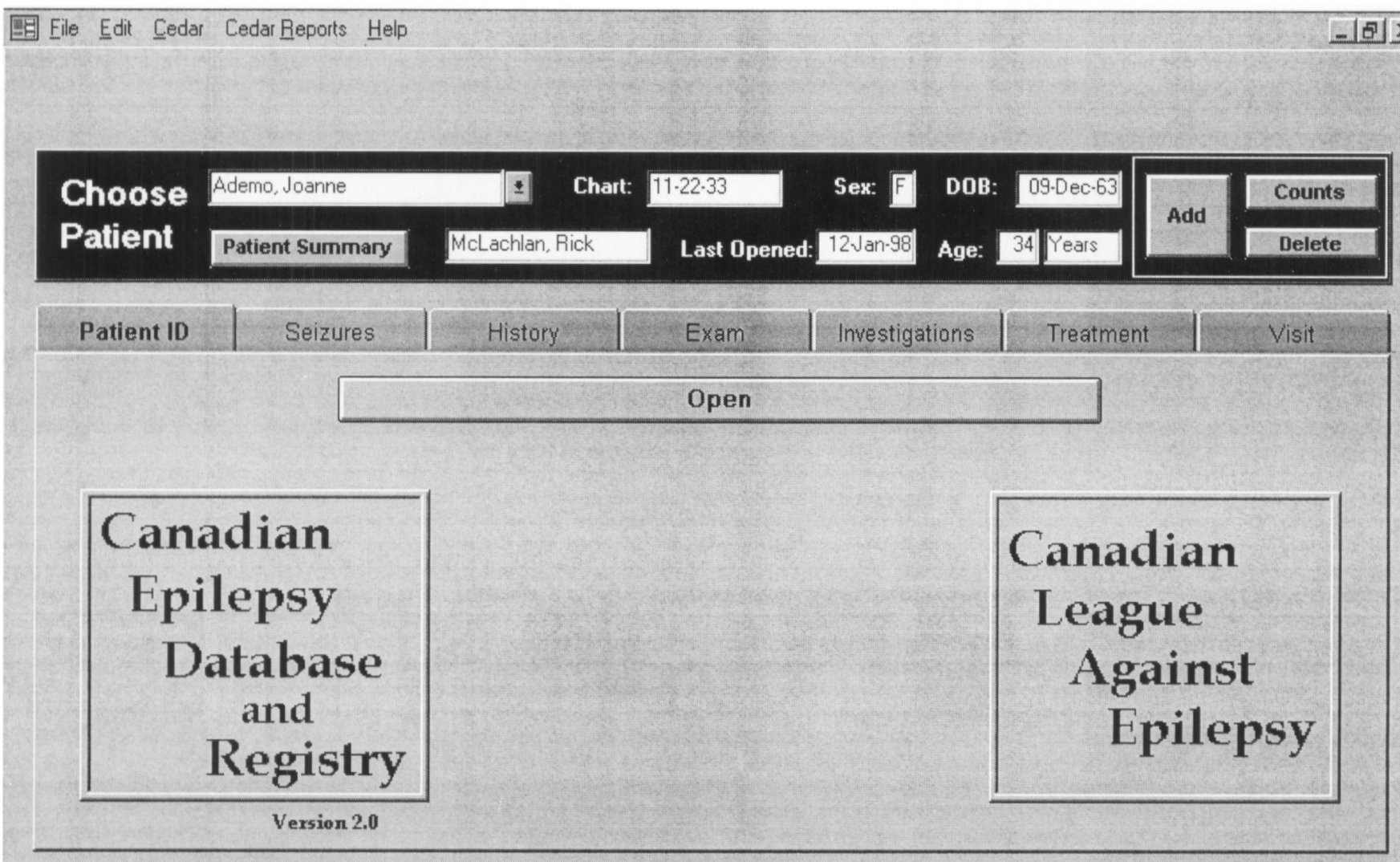

Figure 1: Patients are selected from the main screen of CEDAR and the desired information file is opened. (fictitious patient) 
Etiology Group

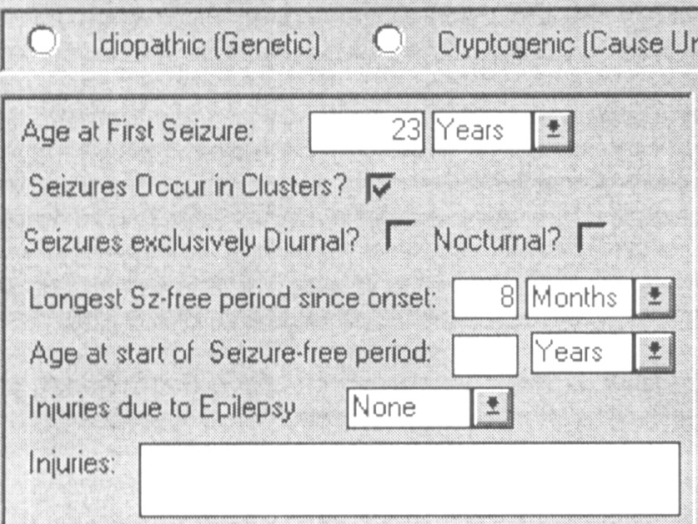

Febrile Seizures

\begin{tabular}{|ll|l|l|l|}
\hline Occurred? $\Gamma$ & Age at First: $\square$ Months & \pm \\
Recurrence? $\Gamma$ & Age Recurred $\square$ Months & \pm \\
\hline
\end{tabular}

Atypical Characteristics

Focal? $\Gamma$ Duration > 30 Minutes? $\Gamma$
Clusters? $\Gamma \quad$ Abnormal Exam? $\Gamma$
Family History - Siblings? $\Gamma$ Others? $\Gamma$

\section{Seizure Types and Epilepsy Syndromes}

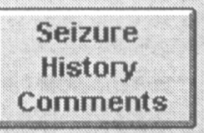

Chart No: $11-22-33$

Afebrile Status Epilepticus

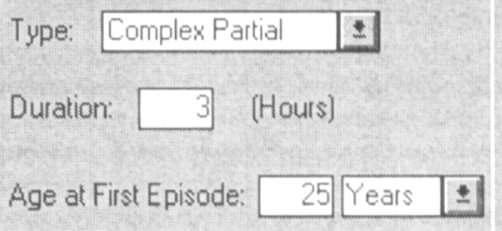

Precipitants
\begin{tabular}{|l|}
\hline Stress \\
Fatigue / Sleep Deprivation \\
\hline Sleep \\
Alcohol \\
Poor Compliance \\
Fever / Infection \\
Photic \\
Exercise / Hyperventilation \\
Menstrual \\
\hline Reflex \\
Startle \\
Other
\end{tabular}

Figure 2: Opening the Seizure file from the Main screen brings up the Seizure History screen. The International Classifications of Seizures and Syndromes is entered from this screen and additional typewritten comments can be entered under "Seizure History Comments".

only selected clinicians or marginally to the whole group. Although CEDAR does not document every piece of information that might be available on a patient, there are numerous fields where additional comments can be typed into the patient

\section{Table 1: Summary Reports.}

\begin{tabular}{ll}
\hline Patients listed by: & -AED \\
\hline & -Seizure type \\
\hline & -Epilepsy syndrome \\
\hline & -Surgery type \\
\hline Seizure classification & -Name \\
\hline Epilepsy syndrome & -ID number \\
\hline AED use & \\
\hline Abnormal test results & \\
\hline Physician directory & \\
\hline Inactive patient list & \\
\hline
\end{tabular}

record. In this regard, it should be kept in mind that databases such as CEDAR are not static but are evolving processes which require changes in content and structure over time. Thus, it is important to design a program from the outset which is flexible and can incorporate such changes. CEDAR allows us to do that and the plan for version 3.0 is to update to Visual Basic or Access 97 as a platform which will provide even greater flexibility and ease of use, particularly in the network environment.

CEDAR is now used by 20 centres across the country (Table 3) but is available through the CLAE for any physician who frequently sees patients with epilepsy. Individual neurologists vary

Table 2: Seizure Classification Summary.

\begin{tabular}{lcc}
\hline Seizure Type* & Number of Patients $(\mathbf{n}=\mathbf{7 5 5 9})$ & Percent of Total \\
\hline Simple partial & 1158 & $15 \%$ \\
\hline Complex partial & 2472 & $33 \%$ \\
\hline Partial evolving to GTC & 1839 & $24 \%$ \\
\hline Generalized & 3629 & $48 \%$ \\
\hline *Patients can have more than one seizure type.
\end{tabular}




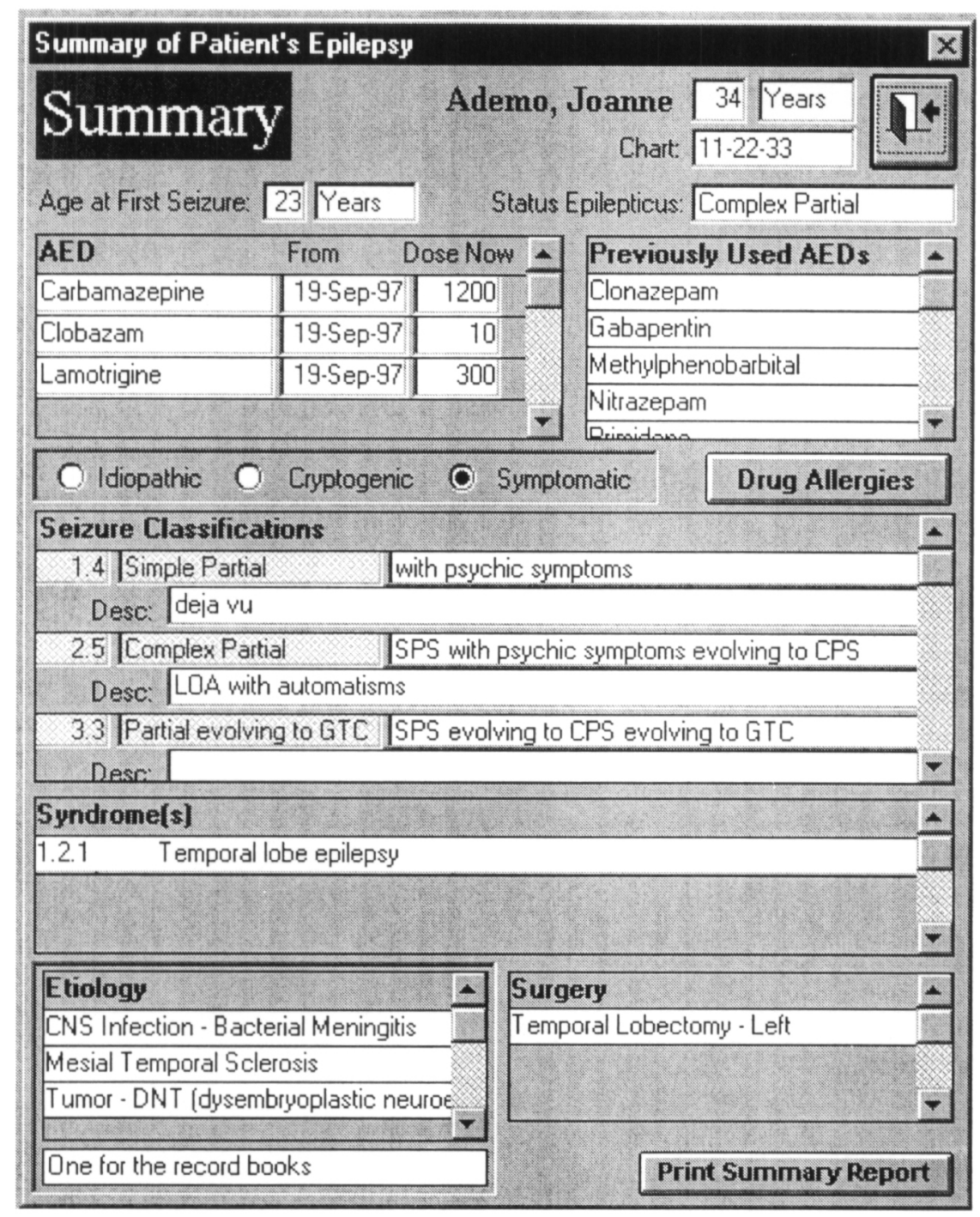

Figure 3: A summary of an individual patient's data is useful for quick reference such as when speaking to a patient on the telephone.

in their use of CEDAR, some documenting basic clinical information only on their patients, while others rely on it as they would the patient's chart. Clinic nurses have found CEDAR to be particularly useful in their follow-up of patients. Initial data

Table 3: Centres Contributing to CEDAR.

\begin{tabular}{ll}
\hline Dr. R.S. McLachlan & London \\
\hline Dr. J. Dooley & Halifax \\
\hline Dr. M. Jones & Vancouver \\
\hline Dr. R. Desbiens & Quebec City \\
\hline Drs. N. Pillay/J. Maher & Winnipeg \\
\hline Dr. G. Ronen & Hamilton \\
\hline Dr. K. Farrell & Vancouver \\
\hline Dr. A. Guberman & Ottawa \\
\hline Dr. J.M. Saint-Hilaire & Montreal \\
\hline Dr. J. Schneiderman & Toronto \\
\hline
\end{tabular}

entry can take 30-45 minutes and is often done by a nurse or other clinical assistant but follow-up information can be entered in two or three minutes. Patient data, stripped of identifying information, is downloaded periodically to the national database

Table 3: (continued).

\begin{tabular}{ll}
\hline Dr. E. Starreveld & Edmonton \\
\hline Dr. B. Sinclair & Edmonton \\
\hline Dr. S. Levin & London \\
\hline Dr. M. Sadler & Halifax \\
\hline Dr. J.D. Buckley & St. John's \\
\hline Dr. M.A. Lee & Calgary \\
\hline Dr. H.Z. Darwish & Calgary \\
\hline Dr. F. Dubeau & Montreal \\
\hline Dr. A. Ogunyemi & St. John's \\
\hline Dr. N. Lowry & Saskatoon \\
\hline
\end{tabular}




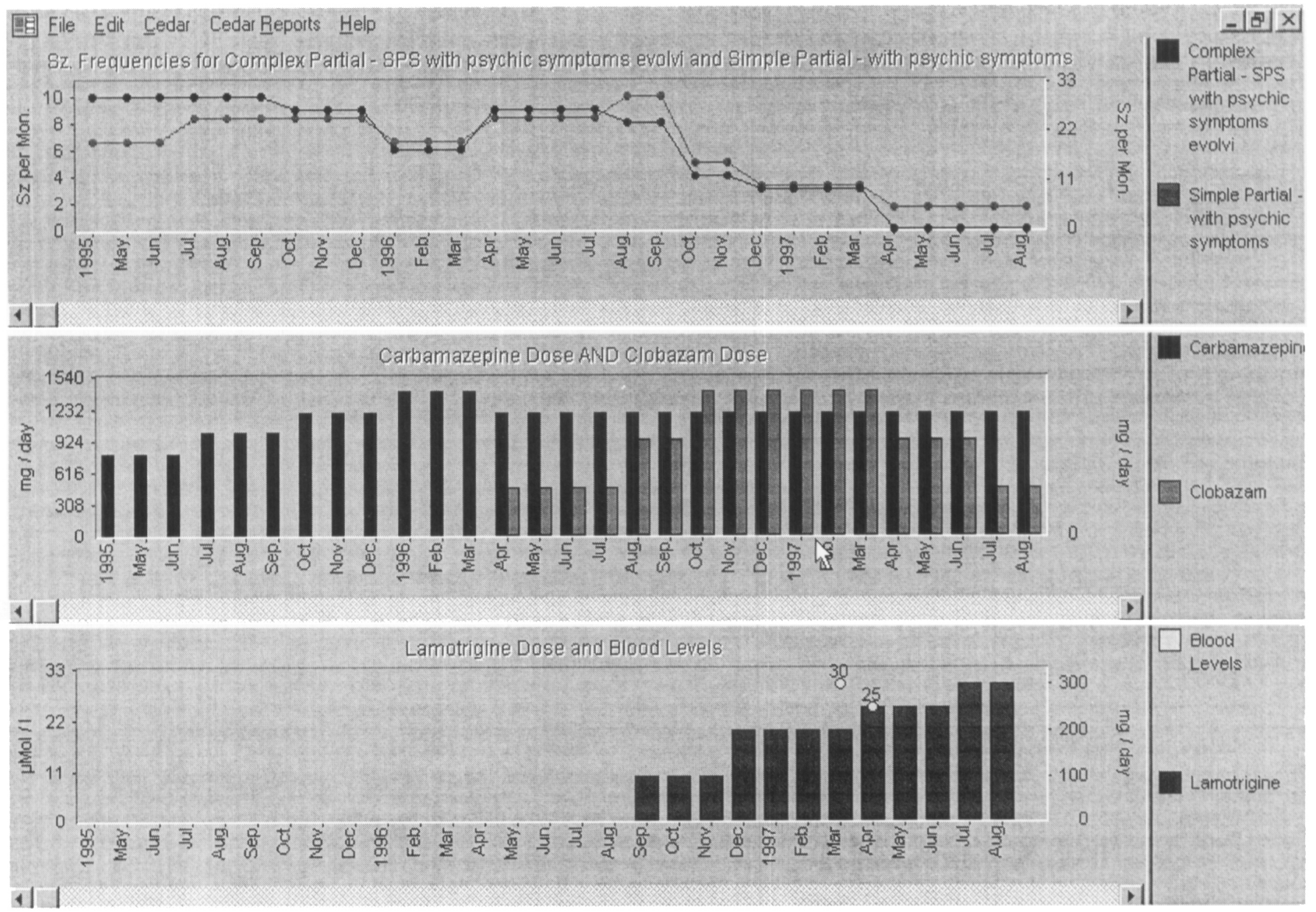

Figure 4: Data from individual patients can be graphed over time based on frequency of different seizure types, drug doses and AED blood levels.

situated in London, Ontario. As of this writing, there were approximately 8000 patients in the database. Our goal of at least 10,000 patients will provide a sound basis to begin some studies on treatment, outcome and epidemiology of epilepsy. As the numbers increase, the power of CEDAR as a research tool will of course grow. With time, it may be possible to incorporate a disease specific database such as CEDAR with other neurological databases (e.g., headache, stroke, multiple sclerosis) to provide a comprehensive and powerful resource for neurology research as well as general neurology office and clinic management.

\section{REFERENCES}

1. McLachlan RS, Dooley J, Casbourne H. Canadian Epilepsy Database and Registry. Epilepsia 1997; 38 (Suppl. 3): 89.

2. Avanzini G. For the Network Epilepsy Centers Regione Lombardia. Survey of the diagnostic and therapeutic approach to patients followed by the Lombardia Epilepsy Network. Epilepsia 1995; 36 (Suppl. 3): 62-63.

3. Commission on Classification and Terminology of the International League Against Epilepsy. Proposal for revised clinical and electroencephalographic classification of epileptic seizures. Epilepsia 1981; 22: 489-501.

4. Commission on Classification and Terminology of the International League Against Epilepsy. Proposal for revised classification of epilepsies and epileptic syndromes. Epilepsia 1989; 30: 389-399. 